\title{
Mood changes in the course of preparation for the Brazilian university admission exam - a longitudinal study
}

\section{Alterações de humor ao longo da preparação para o vestibular - um estudo longitudinal}

\author{
Marco Aurélio Monteiro Peluso, ${ }^{1}$ Carine Savalli, ${ }^{2}$ Mariana Cúri, ${ }^{3}$ Clarice Gorenstein, ${ }^{1}$ Laura Helena Andrade ${ }^{1}$ \\ 1 Institute of Psychiatry, Section of Psychiatric Epidemiology (LIM-23), School of Medicine, Universidade de São Paulo (USP), São Paulo (SP), \\ Brazil \\ 2 Institute of Mathematics and Statistics, Universidade de São Paulo (USP), São Paulo (SP), Brazil \\ 3 Department of Applied Mathematics and Statistics, Institute of Mathematics and Computer Sciences, Universidade de São Paulo (USP), \\ São Paulo (SP), Brazil
}

\begin{abstract}
Objective: Academic examinations are an important source of stress for students. This study is intended to assess senior high school students' mood changes during the preparation for a very important academic examination, the Brazilian university admission examination. Method: Positive and Negative Affect Schedule - Expanded Form was used to assess the students three times in the course of the months preceding the examination. Results: ANOVA for repeated measures showed that Negative Affect increased as the examination approached, and that this increment was already present months before the examination took place. A single conditionally independent random effect model showed that time spent studying was associated with fluctuations in mood. Conclusion: Teenagers, in preparation for a very important examination, may present mood disturbances associated with both the proximity of the examination and their study load months before the examination actually takes place. Other stressing factors may play a role in these findings and should be further investigated.
\end{abstract}

Descriptors: Students; Affect; College admission test; Longitudinal studies; Stress

\section{Resumo}

Objetivo: Exames acadêmicos são uma fonte importante de estresse para estudantes. Este estudo teve como objetivo avaliar alteraçôes de humor em estudantes de terceiro ano do Ensino Médio ao longo da preparação para um exame acadêmico de grande importância, o vestibular. Método: Positive and Negative Affect Schedule - Expanded Form foi utilizado para avaliar os estudantes três vezes ao longo dos meses antecedendo o exame. Resultados: ANOVA para medidas repetidas mostrou que o afeto negativo aumentou com a aproximação do exame e que esse aumento já estava presente meses antes dele acontecer. Um modelo de efeitos aleatórios com independência condicional mostrou que o tempo de estudo estava associado às futuaçôes de humor. Conclusão: Adolescentes em preparação para exames muito importantes podem apresentar um distúrbio de humor associado à proximidade do exame e à quantidade de estudo meses antes que ele ocorra. Outros estressores podem estar associados a esses achados e devem ser investigados.

Descritores: Estudantes; Afeto; Teste de admissão acadêmica; Estudos longitudinais; Estresse

\section{Introduction}

Adolescence is characterized by changes in the physical, cognitive, social and psychosexual domains. The instabilities brought on by these changes make teenagers particularly vulnerable to life stresses, and school-related factors are an important source of daily stress. ${ }^{1,2}$ Studying for examinations and the examinations themselves, the need to reach certain grades, having too much to do, worry over the future, making choices about one's career, the amount to learn, the need to do well (both imposed by others and self-imposed) were found to be the most important sources of stress for senior high school students. ${ }^{1}$

\section{The Brazilian "vestibular"}

"Vestibular" is the name of the university admission examination in Brazil, and will be used to designate it from now on. Many countries have these examinations, but they are usually one of many admission criteria used by universities. In Brazil, the exam is the sole criterion used by most public universities. Considering that these universities offer free tuition and, with few exceptions, are better than the private ones, all Brazilian senior high school students (Brazil has no colleges), from all social classes, are looking for a place at one of them. In summary, the vestibular is a 
high-stakes competitive examination which determines university placement. Anecdotal reports suggest that this examination period is associated with high levels of stress in the candidates. This notion is reinforced by two pertinent studies: Coes $^{3}$ reported a negative association between anxiety and performance in the examination, and Calais, Andrade $\&$ Lipp $^{4}$ reported that stress (defined as a category) is more frequent among students in preparation for the examination than among high school and university freshman students.

\section{Mood studies on high school students}

Most published studies assessing mood in high school students are cross-sectional. Li \& Yen reported that about $70 \%$ of the senior high school students of Hualien City (Taiwan) felt blue, and 25\% felt tense. ${ }^{5}$ Five to $10 \%$ was the rate of prevalence of severe psychiatric symptoms, and stress from schoolwork was one of the predictors of these symptoms (along with difficult peer relationships and neurotic traits). Kouzma and Kennedy reported that female senior high school students scored higher than male on hours spent completing homework, on a self-reported stress measure, and on a mood disturbance measure. ${ }^{6}$ They also found that hours of homework were positively correlated with stress and mood disturbance. Esposito and Clum, investigating high school students identified by school personnel as emotionally disturbed, found that $74 \%$ met criteria for psychiatric disorder and that the strongest predictor of suicidal ideation was severity of depressive symptoms. ${ }^{7}$ One longitudinal study assessed mood variations in this population, ${ }^{8}$ but its focus was on the seasonal mood variations of Swedish high school students, and not on the relationship between mood and school-related stress.

\section{Academic examinations and psychological stress}

The association between academic examinations and psychological stress, as well as its immunological and neuroendocrine markers, has been well documented. ${ }^{9-15}$ Nevertheless, although this kind of study has been done ever since $1914^{16}$ and in that time has generated a considerable amount of scientific literature, there are still some methodological issues that compromise their findings. Stowell reviewed these limitations and made some recommendations for future research. ${ }^{17}$ Among these are use of a within-subjects design and of state anxiety measures.

Furthermore, although mood aspects other than anxiety might be affected, they are not usually assessed. Francis, in a longitudinal study, found that depression and hostility, as well as anxiety, were sensitive to university examinations. ${ }^{9}$ In a cross-sectional design, Farne and Sebellico reported that tension, depression, vigor, fatigue and confusion were associated with academic examinations, but that anger was not. ${ }^{18}$ Also with a cross-sectional design, McIntyre et al. reported that the stress of an imminent examination was associated with an increased Negative Affect, an aspect of affect that reflects a person's general level of subjective distress, but no variation in Positive Affect, which reflects positive emotional experiences. ${ }^{19}$

Finally, Lacey et al., in a prospective study, found that, while changes in cortisol levels occurred just before an important examination was taken, changes in the immune system took place long before it was scheduled (six to eight weeks earlier), showing that the psychological stress may start long before the examination. $^{14}$

\section{Objective and hypotheses}

This study is intended to assess senior high school students' mood changes during their preparation for a very important academic examination, the Brazilian vestibular. The hypotheses tested were: 1) mood changes are associated with the proximity of the examination, 2) these mood changes are detectable months before the examination, 3) these mood changes are more intense among female students, 4) these mood changes are characterized by increased Negative Affect and no variation in Positive Affect, 5) the mood changes associated with the proximity of the vestibular are also associated with the length of time spent studying.

\section{Method}

\section{Participants}

The participants were 222 senior high school students (120 male -102 female, median age $=17$ years, interquartile range $=0$ years). All the 231 students of the senior year from a private high school in São Paulo, preparing for the vestibular, were invited to participate. Nine refused to take part. There were no exclusion criteria. Students were invited to be participants in the study by the first author, in meetings at their school, in the presence of one of their teachers. Prior to any assessment, the study was explained to the participants and written informed consent was obtained on forms approved by the local Institutional Review Board (IRB). Although the participants were mostly under the age of legal majority (18 years), the IRB decided to excuse the researchers from obtaining parental consent because it considered that healthy teenagers, close to the age of legal majority, were able to decide whether or not to participate in a study that posed minor risk, if any.

\section{Instruments}

All participants answered the Positive and Negative Affect Schedule - Expanded Form (PANAS-X), ${ }^{20}$ a self-report rating scale intended, in this study, to assess mood states "during the past week". It consists of 60 items rated on a five-point scale and provides measurement of mood at two different levels: a higherorder level, consisting of two broad dimensions that reflect the "valence" of the mood descriptor (Negative Affect, which includes non-specific symptoms experienced by both anxious and depressed individuals, and Positive Affect, a relatively specific depression cluster of symptoms that reflects anhedonia and the absence of positive emotional experiences); and a lower level, consisting of 11 distinguishable affective states that reflect their specific "content". Fear, Hostility, Guilt, and Sadness, as well as Negative Affect, are negative scales, while Joviallity, Self-Assurance, and Attentiveness, as well as Positive Affect, are positive scales. Shyness, Fatigue, Serenity, and Surprise are considered "other affective states", neither positive nor negative. ${ }^{20}$ For the present study 
the questionnaire was translated into Brazilian Portuguese and validated using exploratory factor analysis and internal consistency measures (Cronbach's alpha). Both methods indicated that the Brazilian Portuguese PANAS-X, when used to assess a young and mentally healthy population, is comparable to the original instrument. ${ }^{21}$

To quantify the time they spent studying, the students were asked to answer the question, "How many hours did you spend studying last week (including routine classes)?”

\section{Procedures}

All 231 students were asked to answer the PANAS-X three times: in March (start of the academic year) 154 of the students answered, in August 208 of them answered, and in late October (15 days before the vestibular) 183 answered. Nine students did not participate in any of the assessments and 122 participated in all of them. The questionnaire was answered at the beginning of routine classes, in the presence of the first author and one of the students' teachers. The students also quantified the time they spent studying (including their routine classes) in the week before each assessment.

\section{Statistical analysis}

The variables considered in this study were the scores of the 13 scales of the PANAS-X. In view of the fact that not all the students took part in all the three assessments, we investigated the possibility of systematic drop-out assessing the differences between students who participated in one, two, or three assessments. Pearson chi-square was used to assess gender distribution, and analysis of variance (ANOVA) was used to compare time studying and the scores of the PANAS-X sub-scales between the groups at each moment, controlling for gender. Analysis of variance for repeated measures (ANOVA-RM), with gender as a factor, was used to compare the scores on the three occasions described above. A first analysis was performed with those students who completed all three assessments. Effect size estimates (partial eta-squared) were made for this analysis. Then, a second ANOVA-RM was performed with all students, including the ones assessed once and twice. To assess the importance of study load for the mood fluctuations, we examined the relation between time studying in the week before the assessment and the scores of the PANAS-X scales, using a single conditionally independent random effect model, ${ }^{22}$ controlling for gender, and using all students assessed. Because this study has no control group, we included an additional analysis aimed at providing a comparison of these senior high school students with a reliable benchmark. We used t-Student for independent samples to contrast the scores of these students in Negative Affect and Positive Affect at point one with the scores of the Brazilian university student normative sample ${ }^{21}$ controlling for gender. The adopted two-sided level of significance for all comparisons was 0.05 .

\section{Results}

The analysis of the possibility of systematic drop-out showed that female students were assessed more often than males (Pearson chisquare $=10.65 ; \mathrm{p}=0.005)$. Considering the PANAS-X sub-scales, among the 39 comparisons (13 scales at three different points), only one showed a significant difference among the students who were assessed once, twice, or three times: Fear, at point three $(\mathrm{F}=3.21 ; \mathrm{p}=0.04)$. The estimate of effect size of this difference, though, was very low (partial eta-squared $=0.035$ ). Finally, time spent studying showed no differences among the groups.

The results of the ANOVA-RM for the whole sample were highly coincident with the results for the sample containing the students assessed three times. Since the whole sample analysis did not add any important findings to the previous analysis, the ANOVA-RM results reported below refer to the sample with the students assessed three times.

We considered that mood changes were associated with the proximity of the vestibular (hypothesis 1) when the ANOVA-RM showed a significant moment effect for the three points (Table 1), and significant effect between points one and three (Table 2). This

Table 1 - Gender effect and moment effect for the three moments, by gender, of the PANAS-X scales, for the sample with the students assessed three times

\begin{tabular}{lccc}
\hline \multicolumn{1}{c}{ Analysis } & Gender effect & Moment effect & Moment effect \\
\hline \multicolumn{1}{c}{ Gender (n) } & $\mathbf{( 1 2 2 )}$ & Male (58) & Female (64) \\
\hline Positive Affect & $\mathbf{F ~ ( 1 , 1 2 0 )}$ & $\mathbf{F ~ ( 2 , 5 7 )}$ & $\mathbf{F ~ ( 2 , 6 3 )}$ \\
Negative Affect & $5.43^{*}$ & 1.07 & 0.41 \\
Fear & $6.90^{*}$ & $16.07^{*}$ & $7.77^{*}$ \\
Hostility & $13.58^{*}$ & $31.11^{*}$ & $7.27^{*}$ \\
Guilt & 0.98 & $9.27^{*}$ & $4.56^{*}$ \\
Sadness & 0.004 & 2.52 & 0.98 \\
Joviality & 0.30 & $7.31^{*}$ & 1.13 \\
Self-Assurance & 0.85 & $4.26^{*}$ & 1.29 \\
Attentiveness & $16.24^{*}$ & 2.11 & 0.15 \\
Shyness & $5.29^{*}$ & $5.70^{*}$ & $3.33^{*}$ \\
Fatigue & $9.71^{*}$ & 1.99 & 0.61 \\
Serenity & 3.14 & $7.62^{*}$ & $5.19^{*}$ \\
Surprise & $31.37^{*}$ & $7.84^{*}$ & 1.59 \\
\hline Significant & 0.03 & $8.97^{*}$ & 1.70 \\
\hline
\end{tabular}

Significant effect $(p \leq 0.05)$ 
Table 2 - Mean scores (M) and standard deviations (sd) of the PANAS-X scales, by gender and moment, for the sample with the students assessed three times

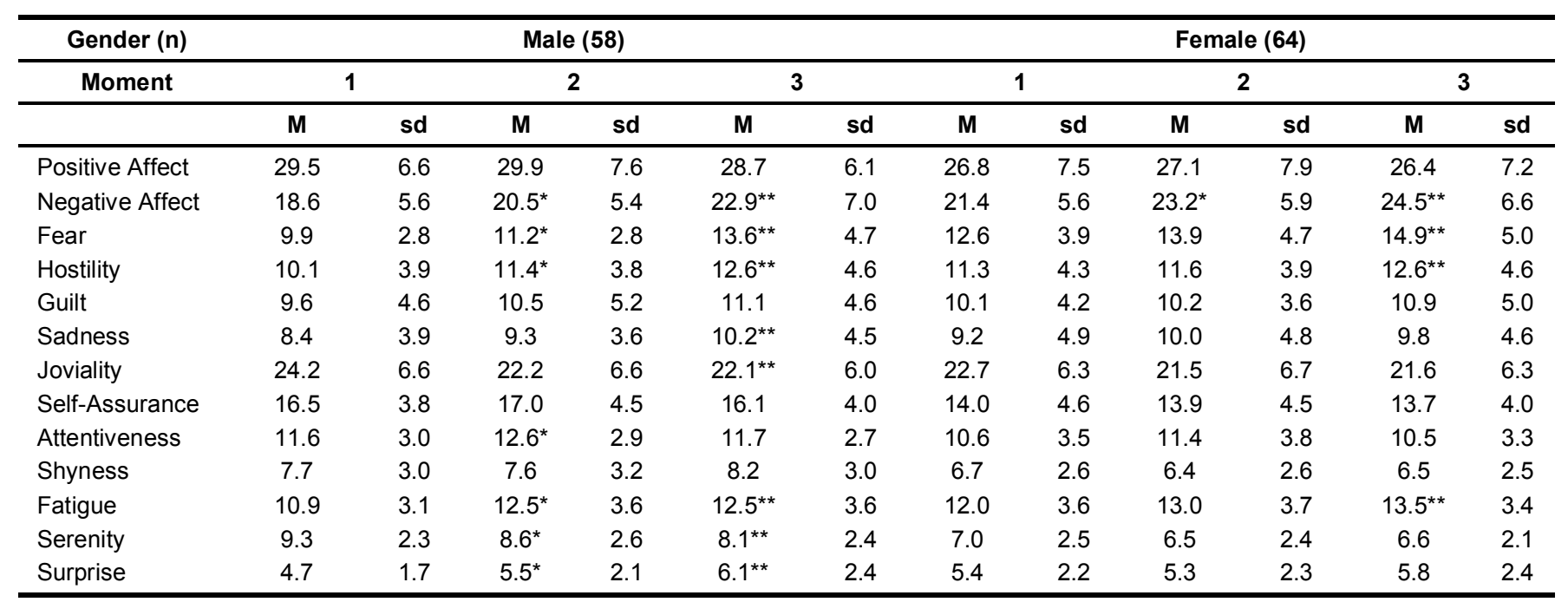

* Significant moment effect, moment 1 vs. moment 2 ( $p \leq 0.05)$.

** Significant moment effect, moment 1 vs. moment $3(p \leq 0.05)$.

pattern occurred with Negative Affect (Figure 1), but not with Positive Affect (Figure 2), for both genders. These results indicate that these mood changes were characterized by fluctuation in Negative Affect but not Positive Affect (hypothesis 4). Among the lower-level negative scales, Fear and Hostility showed this pattern of results for females (Guilt and Sadness showed no variation), and all but Guilt (which showed no variation, either) showed it for males (Table 1). The effect of moment explained a large proportion of variance on Negative Affect (partial eta-squared $=0.22$ ) and Fear $(0.35)$, but smaller proportions on Hostility (0.14) and Sadness (0.11), for male students. For female students, the effect of moment explained only a small proportion of

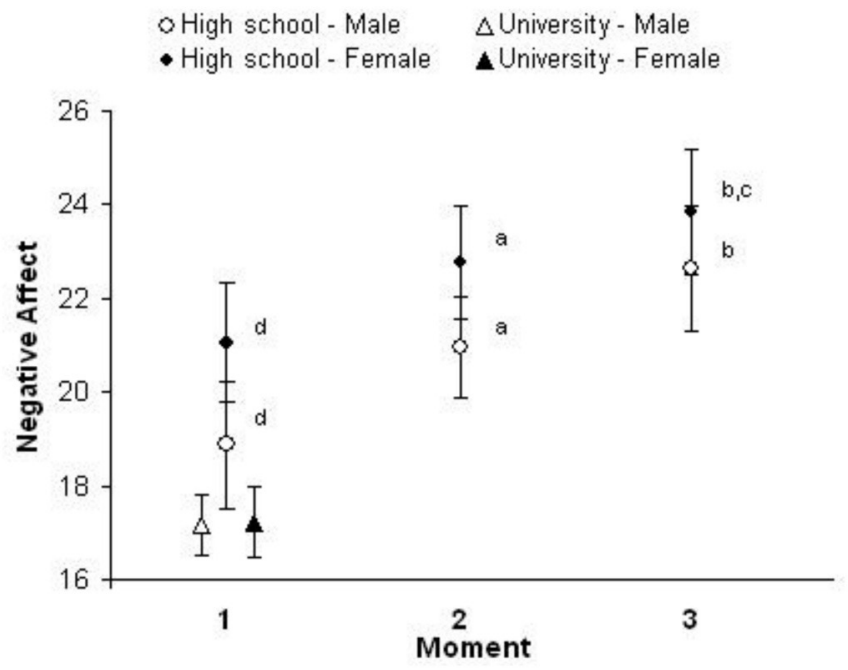

a Significant moment effect, moment 1 vs. moment $2(p<0.05)$

${ }^{b}$ Significant moment effect, moment 1 vs. moment $3(p<0.05)$

${ }^{c}$ Significant gender differences for the three moments $(p<0.05)$

a Significant group differences at moment $1(p<0.05)$

Figure 1 - Mean scores and $95 \%$ confidence interval for the Negative Affect scale, by moment, gender, and group (senior high school students and the Brazilian university student normative sample - Peluso, 2003). variance in Negative Affect (partial eta-squared $=0.11)$, Fear $(0.10)$ and Hostility (0.07). All these negative scale fluctuations were characterized by scores which increased as time went on. None of the positive scales showed a significant moment effect for the three points, or significant moment effect between points one and three, for female students. For male students, only Joviality (which decreased as time went on) showed these results; nevertheless, the effect of moment explained only a small proportion of variance (partial eta-squared $=0.07$ ). Among the "other affective states" scales, Fatigue significantly increased over time, and Shyness showed no significant variation, for either gender. Surprise increased, and Serenity decreased over time for male students, but showed no variation for females (Table 1).

We considered that these mood changes were present three months before the examination (hypothesis 2) when there were mood changes associated with the proximity of the examination (as described above) and significant difference between points one and two. This pattern of results applied to Negative Affect, for both genders, and to Fear and Hostility, for male students but not for females. None of the positive scales showed this pattern of results for male or female students. Amo ng the "other affective states" scales, Fatigue, Serenity, and Surprise had already varied three months before the examination for male students, but none of them showed this variation for females (Table 2).

The possibility of gender effect (i.e. female students showing more intense mood-worsening than males - hypothesis 3) was investigated with ANOVA-RM. Gender x moment interaction was not present on any of the scales. Among the higher-order scales, female students scored significantly more than males on Negative Affect (Figure 1), and significantly less on Positive Affect (Figure 2), for the three points taken together. Among the lower-level scales, female students scored significantly more for the three points taken together on Fear, but scored significantly less on Self-Assurance, Attentiveness, Shyness, and Serenity (Tables 1 and 2). Effect size estimates for most of the scales 


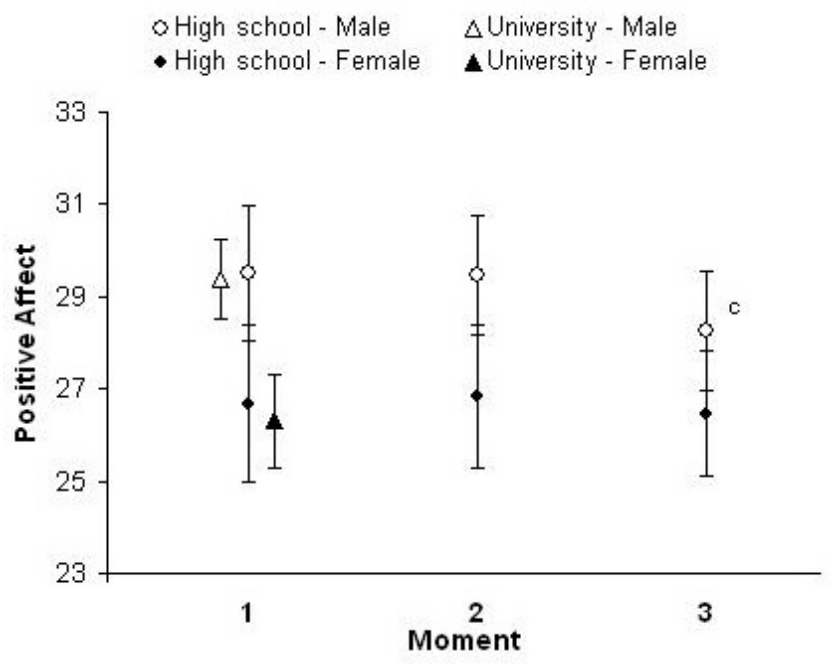

${ }^{a}$ Significant moment effect, moment 1 vs. moment $2(p<0.05)$

${ }^{b}$ Significant moment effect, moment 1 vs. moment $3(p<0.05)$

${ }^{c}$ Significant gender differences for the three moments $(p<0.05)$

${ }^{d}$ Significant group differences at moment $1(p<0.05)$

Figure 2 - Mean scores and 95\% confidence interval for the Positive Affect scale, by moment, gender, and group (senior high school students and the Brazilian university student normative sample - Peluso, 2003).

that showed gender effect were small (partial eta-squared ranged from 0.04 to 0.12 ), with the exception of Serenity (0.21).

The possibility of association between mood changes and time studying (hypothesis 5) was investigated with the single conditionally independent random effect model. The self-reported mean time studying (standard deviation) in the week before each of the three assessments was 33.0 (9.7) hours/week, 44.6 (18.7)h/wk, 41.7 (19.8) $\mathrm{h} / \mathrm{wk}$, respectively, for female students, and $28.0(7.5) \mathrm{h} / \mathrm{wk}, 42.4$ (17.1)h/wk, and 44.6 (17.3)h/wk, respectively, for males. All five negative scales showed significant positive correlations with studying load for male students and three of them (Negative Affect, Fear, and Hostility) showed it for females (Table 2). Among the positive scales, Joviality showed a significant negative correlation, while Attentiveness showed a significant positive correlation, for both genders. Positive Affect and Self-Assurance showed no significant correlations, for both genders. Among the "other affective states" scales, Fatigue showed a significant positive correlation, and Serenity showed a significant negative correlation, for both genders. Shyness and Surprise did not show any correlation for any gender (Table 2).

The analysis aimed to contrast these senior high school students with a reliable benchmark showed that their Negative Affect scores at moment one were significantly higher than the ones of the Brazilian university student normative sample ${ }^{21}$ for male $\left(t_{333}=2.40\right.$, $\mathrm{p}=0.02)$ and female students $\left(\mathrm{t}_{263}=5.27, \mathrm{p}<0.001\right)$ (Figure 1). Positive Affect scores, on the other side, were not different for both genders (males: $\mathrm{t}_{333}=0.15, \mathrm{p}=0.88$; females: $\mathrm{t}_{263}=0.38$, $\mathrm{p}=0.71)$ (Figure 2).

\section{Discussion}

The longitudinal mood assessment performed during the year of preparation for the Brazilian university admission examination showed increasing mood disturbance in both male and female students. Both genders showed increasing scores, as the examination approached, on most of the negative scales, including Negative Affect, and no variation in Positive Affect, and almost all of the other positive scales; findings that were supported by the similar results obtained through comparison with the Brazilian university norms. That is, this study found a mood disturbance associated with the proximity (or anticipation) of the examination, which was characterized by increased Negative Afect and no variation in Positive Affect. This finding showed that the rise in Negative Affect detected by McIntyre et al. immediately before an examination starts to happen a long time beforehand. ${ }^{19}$

Female students showed higher levels of mood disturbance than males on both PANAS-X higher-order scales, replicating Kouzma and Kennedy's findings for this population. ${ }^{6}$ Considering that various international PANAS normative samples did not show gender-related effects for these scales, ${ }^{20}$ this study found unexpected gender differences, that could indicate specific situational effects. Furthermore, the Brazilian university student normative sample, ${ }^{21}$ the most similar available to the sample used for this study, showed females scoring significantly less than males on Positive Affect, but showing no differences in Negative Affect. Therefore, considering the Brazilian norms, that Brazilian female high school students should score less than males on Positive Affect is expected, but that they should score more than them on Negative Affect is not. That is, this study found an unexpected gender difference specifically in the scale that better characterized the worsening of mood related to the examination, possibly indicating that female teenagers are more sensitive to examinationassociated stress than their male counterparts. On the other side, gender $\mathrm{x}$ time interaction was not found on this specific scale, or any other of the PANAS-X sub-scales, showing that, whatever gender effects were found, they were not affected by the fact of the vestibular approaching, at least during the eight-month period that was investigated.

A closer look at the results indicated that these gender differences were mainly influenced by anxiety-related factors. Three different observations support this assertion. 1) Negative Affect, a mood dimension that includes non-specific symptoms experienced by both anxious and depressed individuals, and not Positive Affect, a mood dimension that includes a relatively specific depression cluster of symptoms, ${ }^{20}$ was the higher-order PANAS-X scale that was unexpectedly higher among females. 2) Although the higherorder scale that measures Negative Affect was higher among females, only one of the lower-level scales measuring aspects of Negative Affect showed this same result: Fear, the PANAS-X anxiety scale. 3) Among the seven scales that showed significant gender differences, the effect of gender explained an important proportion of variance on only one: Serenity. Explicitly, among the various individual affective states investigated, higher female susceptibility for anxiety and lower female capacity to maintain serenity were the ones that differentiated the genders most consistently. 
In conclusion, we found unexpected anxiety-related differences between male and female senior high school students, but the bases for these differences are not clear. The hypothesis that the differences found are related to the vestibular does not seem probable, since these differences remained stable during the whole eight months preceding this examination. An alternative explanation would be that these differences happened as a consequence of a drop-out bias. In fact, male students refused to be assessed as often as females did, and bearing in mind the statement made by one of their teachers, "Girls like to talk about their affective issues, boys do not, especially when they are feeling down", it is possible that the male students who refused to participate were the more disturbed ones. Therefore, there is a chance that, if all students were evaluated at every assessment, the gender differences might disappear. Finally, considering that Kouzma and Kennedy found similar results in a senior high school population that was not heading towards the vestibular, that the gender differences found in this study were already present long before the examination, and that they remained stable throughout the year, a final and more probable hypothesis would be that female students may be more susceptible to anxiety-related affective states in response to the usual demands of the senior high school year. ${ }^{6}$

Three months before the examination, in point two, Negative Affect had already increased, in the case of both male and female students, indicating that these students were already affected by mood disturbances three months before the vestibular took place. In addition, Fear, Hostility, Attentiveness, Fatigue, Serenity, and Surprise were sensitive to mood disturbance three months before the examination was scheduled, but only among males. The fact that gender $\mathrm{x}$ time interaction was not detected on any of these (or any other) scales indicates that the time effects found on this study did not differ between the genders and, therefore, that these specific gender differences are probably not very important. Nevertheless, it

Table 3 - Angular coefficient (AC) and standard error (se) of the conditionally independent random effect model for the relation between time studying and scores of the PANAS-X scales, by gender, for the whole sample

\begin{tabular}{lcccc}
\hline \multirow{2}{*}{ Gender } & \multicolumn{2}{c}{ Male $(\mathrm{n}=\mathbf{1 2 0})$} & \multicolumn{2}{c}{ Female $(\mathrm{n}=\mathbf{1 0 2})$} \\
\cline { 2 - 5 } & AC & se & AC & se \\
\hline Positive Affect & 0.01 & 0.02 & 0.03 & 0.02 \\
Negative & & & & \\
Affect & $0.12^{*}$ & 0.02 & $0.11^{*}$ & 0.02 \\
Fear & $0.07^{*}$ & 0.01 & $0.09^{*}$ & 0.01 \\
Hostility & $0.06^{*}$ & 0.02 & $0.05^{*}$ & 0.02 \\
Guilt & $0.04^{*}$ & 0.02 & 0.02 & 0.02 \\
Sadness & $0.04^{*}$ & 0.01 & 0.01 & 0.01 \\
Joviality & $-0.05^{*}$ & 0.02 & $-0.06^{*}$ & 0.02 \\
Self- & & & & \\
Assurance & 0.0003 & 0.01 & -0.01 & 0.01 \\
Attentiveness & $0.03^{*}$ & 0.01 & $0.04^{*}$ & 0.01 \\
Shyness & 0.02 & 0.01 & -0.01 & 0.01 \\
Fatigue & $0.06^{*}$ & 0.01 & $0.06^{*}$ & 0.01 \\
Serenity & $-0.04^{*}$ & 0.01 & $-0.04^{*}$ & 0.01 \\
\hline
\end{tabular}

* Significant correlation $(p \leq 0.05)$ between time studying and scale score (i.e., the null hypothesis, angular coefficient $=0$, was rejected). is interesting to point out that these mood fluctuations, throughout many different distinguishable affective states, detected on this specific point, could possibly indicate the point when the mood of the male students starts to be sensitive to the effects of the vestibular that is, between eight and three months prior to it.

The results of the correlation analysis between time spent studying and the measurements of mood showed that, among the seven scales that showed significant correlation with time spent studying for both genders (Table 3), all but one, Attentiveness, point in the same direction: mood worsens as time spent studying increases. Considering that there is only one exception, and that this exception was not sensitive to the mood disturbance found in this study (Attentiveness showed no time effects between points 1 and 3, for both genders), these findings indicate that the examination-associated mood worsening found among these students is probably associated with time spent studying.

This study has some limitations. Self-report measures imply subjective data that can be distorted. The most frequent way of distorting self-report data is called "social desirability", and happens when the instrument is filled out in a stereotyped and positive manner. As feeling well is considered desirable for good intellectual performance, distortions may have happened. However, considering that the direction of this possible distortion would be to underestimate the mood changes that were found, there is no reason to believe that it has compromised the main findings of this study.

The students assessed in this study are not representative of the whole Brazilian senior high school student population. They are better prepared and, possibly, more confident they will succeed in the vestibular than the majority of Brazilian students. Although these characteristics reduce the possibility of generalizing results, they indicate that even well prepared students present mood disturbances when exposed to the stress of important and demanding examinations.

This study used a within-subjects design, and therefore it had no control group. The lack of a control group limits the strength of the study's findings, and future assessments should include an additional group to control for testing effects.

Finally, it is not possible to isolate completely the stress specifically related to any examination or event, and therefore other factors than examination proximity (or anticipation) and study load may be implicated in the mood changes found. Students preparing for the vestibular usually spend less time on social and leisure activities, have doubts about the careers they are choosing, are insecure about the new responsibilities they are close to assuming, are afraid of losing their friends and the lifestyle they know as they go to university, etc. In fact, the senior high school year is full of expectations and doubts. This study showed that examination expectation and study load are associated with the mood disturbances found among teenage students in preparation for a very important examination, but it did not investigate the relative importance of these and many other possible stresscausing factors. A further research project would help better to understand these causes of mood disturbance, as well as other stress-related mood disturbances. 


\section{Conclusion}

This is the first longitudinal study to show increasing mood disturbance, in both male and female students, during the year of preparation for the Brazilian vestibular. In light of the literature on academic examinations, this study confirms prior findings of mood worsening associated with anticipation of an examination and extends them, showing that, among teenagers, the burden of studying may play a role in this kind of mood disturbance and that, in the case of very important examinations, the mood changes may be present as long as three months beforehand. The study also corroborates the finding that the mood changes associated with academic examinations are characterized by increase in Negative Affect and no fluctuation in Positive Affect. Finally, it replicates and extends previous findings of gender mood differences among senior high school students, indicating that females may be more susceptible to anxiety-related affective states in response to the demands of the senior high school year.

\section{Acknowledgements}

This research was partly supported by Fundação de Amparo à Pesquisa do Estado de São Paulo (FAPESP - 01/01414-6). MAMP was supported by grants of FAPESP (99/10196 and 00/11316-9).

Disclosures

\begin{tabular}{|c|c|c|c|c|c|c|c|}
\hline $\begin{array}{l}\text { Writting group } \\
\text { member }\end{array}$ & Employment & $\begin{array}{l}\text { Research } \\
\text { grant }^{1}\end{array}$ & $\begin{array}{c}\text { Other research grant } \\
\text { or medical continuous } \\
\text { education }^{2}\end{array}$ & $\begin{array}{l}\text { Speaker's } \\
\text { honoraria }\end{array}$ & $\begin{array}{l}\text { Ownership } \\
\text { interest }\end{array}$ & $\begin{array}{l}\text { Consultant/ } \\
\text { Advisory } \\
\text { board }\end{array}$ & Other $^{3}$ \\
\hline $\begin{array}{l}\text { Marco Aurélio } \\
\text { Monteiro Peluso }\end{array}$ & $\begin{array}{l}\text { NEP-IPq-HC- } \\
\text { FMUSP }\end{array}$ & FAPESP ${ }^{* *}$ & - & - & - & - & - \\
\hline Carine Savalli & UNIFIEO & - & - & - & - & - & - \\
\hline Mariana Cúri & ICMC-USP & FAPESP ${ }^{* *}$ & - & - & - & - & - \\
\hline $\begin{array}{l}\text { Laura Helena } \\
\text { Andrade }\end{array}$ & $\begin{array}{l}\text { NEP-IPq-HC- } \\
\text { FMUSP }\end{array}$ & FAPESP ${ }^{* *}$ & - & - & - & - & - \\
\hline \multicolumn{8}{|c|}{$\begin{array}{l}{ }^{*} \text { Modest } \\
\text { ** Significant } \\
\text { *** Significant. Amounts given to the author's institution or to a colleague for research in which the author has participation, not directly to the } \\
\text { author. } \\
\text { Note: NEP-IPq-HC-FMUSP = Núcleo de Epidemiologia Psiquiátrica do Instituto de Psiquiatria do Hospital das Clínicas da Faculdade de Medicina } \\
\text { da Universidade de São Paulo; UNIFIEO = Centro Universitário Fundação Instituto de Ensino para Osasco; ICMC-USP = Instituto de Ciências } \\
\text { Matemáticas e de Computação da Universidade de São Paulo; LIM-23-IPq-HC-FMUSP = Laboratório de Psicopatologia Experimental e } \\
\text { Psicofarmacologia do Instituto de Psiquiatria do Hospital das Clínicas da Faculdade de Medicina da Universidade de São Paulo; FAPESP = } \\
\text { Fundação de Amparo à Pesquisa do Estado de São Paulo; CNPq = Conselho Nacional de Desenvolvimento Científico e Tecnológico. } \\
\text { For more information, see Instructions for authors. }\end{array}$} \\
\hline
\end{tabular}

References

1. Kouzma NM, Kennedy GA. Self-reported sources of stress in senior high school students. Psychol Rep. 2004;94(1):314-6.

2. Li YM, Yen LL. Daily life stress and its correlates among high school students in Hualien city. Kaohsiung. J Med Sci. 1998;14(4):234-41.

3. Coes MC. Test anxiety: a quantitative evaluation of its effects on the Brazilian college entrance examination. Psic Teor Pesq. 1991;7(2):137-47.

4. Calais SL, Andrade LMB, Lipp ME. Sex and schooling differences in young adults stress manifestation. Psicol Reflex Crit. 2003;16(2):257-63.

5. Li YM, Yen LL. Self-rated psychiatric symptoms and their correlates among senior high school students in Hualien City. J Formos Med Assoc. 1998;97(9):593-9.

6. Kouzma NM, Kennedy GA. Homework, stress, and mood disturbance in senior high school students. Psychol Rep. 2002;91(1):193-8.

7. Esposito CL, Clum GA. Psychiatric symptoms and their relationship to suicidal ideation in a high-risk adolescent community sample. J Am Acad Child Adolesc Psychiatry. 2002;41(1):44-51.

8. Rastad C, Ulfberg J, Sjoden PO. High prevalence of self-reported depressive mood during the winter season among Swedish senior high school students. J Am Acad Child Adolesc Psychiatry. 2006;45(2):231-8.

9. Francis KT. Psychologic correlates of serum indicators of stress in man: a longitudinal study. Psychosom Med. 1979;41(8):617-28.

10. Jemmott JB 3rd, Magloire K. Academic stress, social support, and secretory immunoglobulin A. J Pers Soc Psychol. 1988;55(5): 803-10.

11. Spangler G. Psychological and physiological responses during an exam and their relation to personality characteristics. Psychoneuroendocrinology. 1997;22(6):423-41.

12. Maes M, Van Der Planken M, Van Gastel A, Bruyland K, Van Hunsel F, Neels H, Hendriks D, Wauters A, Demedts P, Janca A, Scharpé S. Influence of academic examination stress on hematological measurements in subjectively healthy volunteers. Psychiatry Res. 1998;80(3):201-12.

13. Deinzer R, Kleineidam C, Stiller-Winkler R, Idel H, Bachg D. Prolonged reduction of salivary immunoglobulin A (sIgA) after a major academic exam. Int J Psychophysiol. 2000;37(3):219-32.

14. Lacey K, Zaharia MD, Griffiths J, Ravindran AV, Merali Z, Anisman H. A prospective study of neuroendocrine and immune alterations associated with the stress of an oral academic examination among graduate students. Psychoneuroendocrinology. 2000;25(4):339-56.

15. Ng V, Koh D, Mok BY, Chia SE, Lim LP. Salivary biomarkers associated with academic assessment stress among dental undergraduates. J Dent Educ. 2003;67(10):1091-4

16. Folin O, Denis W, Smillie WG. Some observations on "emotional glycosuria" in man. J Biol Chemistry. 1914;17(4):519-20.

17. Stowell JR. Use and abuse of academic examinations in stress research. Psychosom Med. 2003;65(6):1055-7.

18. Farne M, Sebellico A. Test anxiety: various aspects. Boll Soc Ital Biol Sper. 1989;65(6):571-3.

19. McIntyre CW, Watson D, Cunningham AC. The effects of social interaction, exercise, and test stress on positive and negative affect. Bull Psychonomic Soc. 1990;28(2):141-3.

20. Watson D, Clark LA. Manual for the positive and negative affect schedule expanded form. Unpublished manuscript: University of Iowa; 1994.

21. Peluso MAM. Mood alterations associated with intense physical activity [dissertation]. São Paulo: Faculdade de Medicina, Universidade de São Paulo; 2003.

22. Diggle PJ, Liang K, Zeger SL. Parametric models for covariance structure. In Diggle PJ, Liang K, Zeger SL, editors. Analysis of longitudinal data. New York: Oxford Science Publications; 1984. p. 78-116. 